\title{
What Organisms Once Were and Might Yet Be
}

\author{
Christopher Shields*
}

\begin{abstract}
Organisms receded from view in much of twentieth-century biology, only to undergo a sort of renaissance at the start of the twenty-first. The story of why this should be so is complicated and fascinating, but belongs primarily to the history of biology. On the other hand, to the extent that it is so, a question naturally arises: what, after all, are organisms? This question has a long and complicated history of its own, both within and without of biology; an investigation of this history yields some guidance as to how organisms might yet be conceived today. One suggestion borne of these investigations is this: organisms are, for better or worse, normatively delineated unities.
\end{abstract}

\section{Keywords}

organism $\bullet$ Aristotle $\bullet$ teleonomy $\bullet$ teleology $\bullet$ unity $\bullet$ autonomy $\bullet$ hylomorphism

Part of a special issue, Ontologies of Living Beings, guest-edited by A. M. Ferner and Thomas Pradeu

Editorial introduction: Christopher Shields works at the intersection of ancient philosophy and metaphysics. In this paper, he moves between both fields in examining the concept of the 'organism.' He treads territory similar to John Perry's (in his 'Identity and SelfKnowledge'), insofar as his aim is to render more precise a philosophical-cum-biological concept such that it might be more subtly applied in the philosophy of biology.

As will be familiar to philosophers of biology (if not animalists), the organism concept is a profoundly vexed one. Its usefulness in biological theorizing is not always obvious. As a result, for those science-minded metaphysicians whose ontological call-sheets include only such entities as are necessary posits for their best theories, the organism's ontological status is sometimes held in doubt. Are organisms really real? What is their metaphysical character? (Examining these questions will lead to questions at higher levels of generality, about substances and aggregates — as discussed in Stéphane Chauvier's 'Individuality and Aggregativity').

*Department of Philosophy, 101 Malloy Hall, University of Notre Dame, Notre Dame, IN 46556, USA, cshield3@nd.edu

Received 14 November 2016; Accepted 15 February 2017 doi:10.3998/ptb.6959004.0009.007 
Shields responds to the apparent discrediting of the organism concept by isolating one historical usage of the term (among a variety) and demonstrating its continued relevance. His picture of the organism is an Aristotelian one, and his analysis emphasizes the centrality of the notion of unity. Doing so, he shows how ontological dependence can be cashed out in teleological terms, in a manner that neatly parallels the discussion of the same in Rory Madden's 'Animal Self-Awareness' (and simultaneously, and implicitly, challenges how philosophers of biology are beholden to causality in their metaphysical discussions). The Aristotelian turn is obviously a contentious one-and one which might unsettle philosophers of biology - but Shields is careful and his analysis subtle.

The examination of organic unity also extends into the theoretical correlates of wholeness and part-hood. As such, Shields's paper is an excellent resource for those working on 'biological modularity'-like Catherine Kendig and Todd Eckdahl, in their paper 'Reengineering metaphysics.' Investigating modularity and evolvability (in relation to the BioBrick assembly method), one needs sturdy notions of part-hood and wholeness. In rendering these concepts more precise, Shields's article also stands as a useful partner piece to Fridolin Gross and Sara Green's 'The Sum of the Parts: Large-Scale Modeling in Systems Biology.' $-\mathrm{AF} / \mathrm{TP}$

There was a time when 'organism' had a clear, uncontested meaning. Or, more exactly, there was a time when the Greek word öpyavov, from which our word 'organism' rather circuitously descended, had a clear meaning, and the story of the semantic and categorial shifts along the path of its descent is telling and instructive along several dimensions. ${ }^{-1}$ For in the process of developing its current meaning, 'organism' shifted in such a way that it is no longer precisely clear what, if anything, it means. That at any rate provides at least part of the motivation and justification for the present volume: both within and without of the life sciences, we are unsure even about the term's extension, to the point where some argue that its extension is the null set. Some simply contend, that is, that there are no organisms. So, the philosopher of biology Michael Ruse is happy to take seriously the possibility that there simply are no organisms, at least not in any sense relevant to the practice of biology: 'Do organisms exist? Well, yes ... and no ....' They exist in a loose and popular way, but there seems little role for a more precise, suitably reduced, empirically respectable notion for them to play in the biological sciences. Moreover, as he maintains, 'from the perspective of the working scientist, this hardly matters.' One motivation for advancing this extreme-sounding thesis turns out to be familiar and in itself not at all extreme. Perhaps the term has simply outlived its theoretical usefulness, such that whatever afterlife it may enjoy in popular discourse, it simply no longer has any purchase in the life sciences. Organisms have, rather, quietly followed Lamarckian inheritance onto the discard

\footnotetext{
${ }^{1}$ In studying this history, I have benefited from the detailed and informed work of Cheung (2010, and esp. 2006), which concentrates, however, on the developments of the $17^{\text {th }}$ to the $19^{\text {th }}$ centuries. In reaching back to a still earlier period one might hope to provide a broader context by charting the ways in which the relevant terms shifted to something independent and substantival from something (or so I argue) precisely dependent and, if substantival at all, only so in a dependent sort of way. Proceeding this way serves to highlight one extremely useful feature of Cheung's discussions, namely his suggestion that we are often best in a position to know a term's meaning when we know that term's contrast class. That said, to be clear, my aim in this paper is not linguistic; I urge instead that one may usefully begin thinking about the nature of organisms by reflecting on how we have struggled to speak about them. The semantic shifts one observes, I suggest, help bring an underlying issue about the nature of organisms into sharper relief. See also n. 3 below.

${ }^{2}$ Ruse (1989, 1061 and 1066).
} 
pile of outmoded ideas.

To the extent that this is so, one might wonder about the point of looking backward to investigate the history of the concept, especially by reflecting, as we will, on a markedly preDarwinian use of the term. After all, the word 'organism' is hardly beholden to its etymological roots. Like other words, its meaning has developed, shifted, and shaded through times and contexts, perhaps even to the point of having outlived its usefulness in serious empirical discourse. Still, there is a point in returning to its semantic parentage beyond some presumed etymological fascism: its original meaning has a decided advantage over some later appropriations, namely that it carried with it a clear prescription for unity, which is precisely one of the contentious issues regarding any approach to the nature of organisms today. This suggests one of several ways, then, in which what organisms once were might be helpful to determining what they may yet still be; the exercise into the original meaning of 'organism' is accordingly not offered as a lexical or narrowly semantic enterprise, interesting though such an investigation might prove to be. ${ }^{\beta}$ Rather, the aim of the exercise is to suggest that by reflecting on what organisms once were we may arrive at a conception of how they might best be conceived today-namely, in Neo-Aristotelian terms, as intrinsic teleonomic unities. Some might bristle at the unapologetic appeal to teleology in this approach, countering, as is not uncommon, that teleological explanation has shown itself to be moribund, that its presumed utility ended already several centuries ago. Perhaps. If so, then, it would follow that there are no intrinsic teleonomic unities. . $^{\text {That }}$ is indeed a possibility; but then it is also equally a possibility that there are no organisms either. For some this will be a happy outcome; as has already been suggested, there are those according to whom this is not a mere possibility but rather simply the current and correct state of play.

\footnotetext{
${ }^{3}$ To some of us, at any rate, the story of the word's original meanings and many developments and extensions is fascinatingly complex - and this is already so attending only to the Indo-European linguistic context. In current usage in English, for instance, an organism is in the first instance, as the OED offers, 'an individual animal, plant, or single-celled life form.' So conceived, it is natural to say, as for instance Lamb says in his The Essentials of Physiology $2^{\text {nd }}$ ed. (1984): 'All living organisms are composed of cells.' What the OED does not say, though which is perfectly reflected in their root definition, is that the word is by now fully substantival, a count noun, and no longer purely functional or relational, as, say, the word 'tool' is. The route to this semantic situation is complex, not least because the root of the English word is mildly in dispute among lexicographers. It is, remotely, the Greek word öpyavov, with a primary meaning of tool or implement, but then also used to refer to the organs of the body, sundry musical instruments, and then even, in post-classical Greek, the science of logic, conceived as a tool for philosophy and other theoretical inquires. Along its journey into English, the post-classical Latin word organum seems to have been borrowed twice over into Old English, once from Old French and once from Germanic sources, in the first instance referring to musical instruments and then later, separately, to bodily organs; the two words merged in Middle English and thereafter, though of course even now we retain in English the range of meanings implied in this development, from pipe organs and bodily organs to conduits of communication and sliding into various euphemisms for the male, well, organ. The etymological investigations of the history and development of the term do make for good reading, but this is not, to repeat, our present enterprise. Rather, we mean to isolate one clear original meaning in an effort to shine a spotlight on how organisms might be conceived.

${ }^{4}$ In speaking of 'teleonomic' unities I draw on Shields (2012). The term is not introduced as a sort of camouflage - as a more respectable way of speaking of teleology—as one referee wryly suggested, but is instead intended to indicate that the notion of teleology pertinent to living systems generally is made more contentful by insisting that end states serve as unifying principles for normatively characterized subordinate processes in law-like and projectable ways. In speaking this way I find myself in substantial agreement (about the claim, not the word) with Walsh (2006, 2010, and 2014), whose empirically informed arguments are well worth consulting.
} 


\section{Whither Organisms?}

The first half of the twentieth century witnessed a sustained interest in the nature of organisms, replete with questions about the manner and mechanism of their self-organization, many concerning how organisms co-ordinated subsystems, but others, at a higher level of generality, concerning the very nature of organisms themselves. 5 Thereafter, interest in organisms waned. Very briefly, the decline in interest was consequent upon the twin rise of microbiology and population biology, neither of which took the organism as a fundamental explanatory posit. ${ }^{\text {G }}$ In one direction, the Modern Synthesis of Darwinian evolution with Mendelian genetics yielded a fertile framework of inquiry at the level of populations, whilst in the other molecular biology adopted the analytical techniques of biochemistry, yielding a second pole of activity focussed on seeking to explain cellular phenomena in terms of macro-molecular structure. Such a view left no room for an independent consideration of the organism, which was seen as 'nothing more than an epiphenomenon of its genes' (Nicholson 2014, 348). To those focussed on genetic phenomena, the gene simply displaced the organism as the locus of biological explanation.

In this narrative, the organism simply fell between the cracks of two levels of explanation. There is, however, also a Leitmotiv of sorts in this story. This is that some who noticed the demise of the organism as a locus of investigation early on attributed the cause not merely to the bifurcation of biology into the small, the gene, and the large, the population, but saw this bifurcation itself as a consequence of a much earlier development, one emerging already at the start of the twentieth century. This was the suggestion of Webster and Goodwin (1982), who took the view that the disappearance of the organism was due in the first instance to the pioneering work of the German biologist August Weismann, much of which appeared already in the late nineteenth century. Weismann had argued that inheritance worked through germ cells only, such that other somatic cells played no role as hereditary agents. Germ cells contain heritable traits, he argued, whereas somatic cells do not; somatic cells then carry out other normal bodily functions not implicated in matters pertaining to heritability. On his approach, then, germ cells are in effect walled off from environmental factors, impervious to morphological changes in the organism as a whole as well as to environmental influences more generally. One upshot of Weismann's work was to limit the explanatory role of the organism as a serious contributor to biological development; the action was thus moving already to the sub-organic. The germ cells, such as the gametes, became the drivers in genetic transmission. From there-especially after the recovery of Mendelian genetics in the early twentieth century-it was a smallish step to enrich and render precise the terms within which sub-organismic development were to be construed. Weismann's work did not set out to downgrade the status of the organism; neither did the work of those following in his wake take this as their aim. Rather, the work of Weis-

\footnotetext{
${ }^{5}$ This history is clearly and intelligently discussed by Nicholson (2014), to whose work the brief summary offered here is indebted. Nicholson charts the demise and return of the organism as a topic of interest in theoretical biology and the philosophy of biology, but does not undertake to analyze any particular account of organisms. For an informative discussion alive to various social dimensions of biological trends, see also Peterson (2014).

${ }^{6}$ Nicholson describes these developments succinctly and accurately: 'The second half of the twentieth century witnessed the disappearance of the organism as a fundamental explanatory concept. The epistemological focus shifted to sub-organismic entities (like genes) on the one hand, and to supra-organismic entities (like populations) on the other. The category connecting them, the organism as a whole, fell between the cracks of biological enquiry' $(2014,347)$. As we see in the text below, there is more to the story than Nicholson suggests, though, to be fair, he is attempting a summary overview rather than a detailed study in the work cited.
} 
mann and his followers presaged the slow death of the organism as an explanatorily infertile postulate simply by changing the focus to sub-organismic phenonema. The organism was not killed; it simply atrophied.

It bears re-emphasizing that these explanations of the death of the organisms are not in competition with one another. On the contrary, they in fact complement each other in one important respect, and it is a respect which will play a role in our story further on. The organism receded as a fundamental explanatory posit not because it was taken to be inherently problematic or somehow incoherent. It merely became otiose in the practice of biology. The organism proved to be, so to speak, on the driven rather than the driving end of the causal direction of living systems. Developmental biology requires some manner of agent, pushing a genetic program capable of determining how living systems develop and decline. Organisms played no active role in this story, but were seen to be directed and developed by other purported agents of biological development, and so as at most epiphenomenal. Without any immediate, autonomous causal work of their own to do, organisms fell by the wayside.

As far as this story goes, there is no harm in speaking of organisms loosely or popularly, as we may freely speak of the setting of the sun at the end of its daily journey-as long as we remain aware that we do not in fact live in a geocentric universe. Organisms are not actually a threat to biological explanation, and so there is from that perspective no harm in referring to them-again, as long as we do not take ourselves to be speaking rigorously and accurately when we do. We err only when we speak of them as if they were agents worthy of the name.

This last point proves significant in the further development of their more recent fate. For it turns out that this story of their slow demise notwithstanding, organisms have been making a comeback. This is arguably due to a variety of factors, some more technical and some less so. On the more technical side of the equation, Jablonka and Lamb (2005) have contended that epigenetic factors do after all play a role in inheritance and development. As a result, we have seen the rise of Developmental Systems Theory (Oyama 2000, 2001), according to which epigenetic factors play a role in development alongside genes, as well as arguments to the effect that phenotypical plasticity plays a causally independent role in adaptive development (WestEberhard 2003, 2005; Walsh 2006, 2010, 2012, 2014). In their different ways, these theorists have looked to extra-genetic features of organisms as adaptively and developmentally active, so as to undermine the claim of the gene as the sole or even privileged driver in these areas. In so doing, they have re-introduced the organism as an explanatorily relevant factor in development, adaptation, and inheritance. The suggestion is not, of course, that organisms pre-empt other forms of explanation, but rather that they play a role alongside micro- and macro-phenomena in the biological sciences. Neither is the suggestion that these may now be regarded as settled matters. Rather, one witnesses an internal dialectic in these discussions, in which the status of the organism waxes and wanes and then waxes again. We may assume that the story has chapters yet to be written.

\section{The Original Meaning of Organic}

As these chapters are written, it behoves the writers to bear in mind that the notion of organism to which the parties to these disputes appeal is hardly innocent. For there is a prior question of

${ }^{7}$ As Nicholson $(2014,349)$ reports: they have called attention to 'a number of Neo-Lamarckian epigenetic inheritance mechanisms (such as chromatin marking processes like DNA methylation, positive feedback loops of gene expression, RNA interference, and the template-based replication of membranes and prions).' 
greater generality lurking behind the disputes, namely: what is an organism? One can appreciate this already by noting that the disputes just catalogued fall into two broad, clearly related categories: (i) disputes about the extension of 'organism,' which is to say, put into the material mode, disputes about which things fall into the class of organisms and which do not; and (ii) disputes about the meaning, or, put into an idiom some find itself outmoded, about the nature or essence of organisms. These are related if we think that (ii) determines (i), or, in the order of discovery, if we think that a survey of paradigm cases of (i) guides us towards a specification of (ii). Of course, there will be those who despair of a meaningful discussion of both (i) and (ii), but, evidently, those whose views we have just characterized are not among their number.

From one perspective, however, there is something peculiar and noteworthy about a presupposition shared by all parties to this dispute: all seem to have their sights trained on the question of what organisms are, understood in a specific way according to which organisms are thought to be autonomous living beings, beings which are somehow substantial in their own right, beings which, even if they are causally dependent upon other beings for their existence, as are parasitic and symbiotic organisms of various sorts, never the less exhibit a sufficient degree of autonomy that we are inclined or at least tempted to think of them as organisms in the first place, as opposed, for instance, to artefacts or parts of organisms, or features of organisms.

For example, let us suppose that Matisse is feeling blue. No one is tempted to think of his mood as an organism; nor does anyone think of the toenail of the large toe on his left foot as an organism either, even though it plays a significant function in his somatosensory system. Still less are we tempted to think of his paint-smeared blue forearm as an organism, even though the paint and his forearm are chemically bonded in a variety of non-trivial ways. Why not? Evidently we do so in some measure because we are assuming that such parts and features fail some minimal autonomy condition for organisms. We think, that is, that an $x$ is an organism only if $x$ has some manner of ontological independence, the sort of independence that a smear of paint, a mood, or a toenail lacks. If this is so, then we find ourselves able to identify a presupposition of the inquiry in general, namely that organisms are, in some specifiable way, more than causally autonomous beings.

This is a presupposition that is from one perspective at any rate peculiar, and even alien. That perspective is Aristotle's. In his De Anima, he develops and defends a hylomorphic conception of living beings, according to which, in his terminology, animate beings are composites of form and matter, where the form of a living being is a soul (psuchê) and its matter a certain sort of body:

Hence, the soul is the first actuality of a natural body which has life in potentiality. This sort of body would be one which is organic (ỏpyavikóv). And even the parts of plants are organs, although altogether simple ones. For example, the leaf is a shelter of the outer covering, and the outer covering of the fruit; and the roots are analogous to the mouth, since both draw in nourishment. Hence, if it is necessary to say something which is common to every soul, it would be that the soul is the first actuality of an organic natural body. ( $D A$ ii $1,412 \mathrm{a} 27-\mathrm{b} 5)$

There is, of course, a fair bit of technical terminology in this definition of the soul, much of which came to be regarded with a jaundiced eye in the fifteenth and sixteenth centuries and afternot least, to be sure, Aristotle's appeals to the notions of potentiality (dunamis) and actuality (energeia and entelecheia). These notions came in for a good deal of stick at the hands, for

\footnotetext{
${ }^{8}$ For a clear, detailed presentation of recent work on organizational closure, see Mossio and Moreno (2014).
} 
instance, of Gassendi, who was thrown into a sour mood in response to Aristotle's definition of motion (kinêsis) as the 'actuality (entelecheia) of what is in potentiality (en dunamei) qua such': 'Great God! Is there any stomach strong enough to digest that? The explanation of a familiar thing was requested, but this is so complicated that nothing is clear anymore. ${ }^{19}$ Others have had similar responses to other features of this definition, including the notions of form (eidos) and matter (bulê), each of which has proven to resist ready explication.

For our purposes, we need only reflect that Aristotle's definition here is an application of his general doctrine of hylomorphism, according to which living beings and ordinary artefacts are metaphysically complex: they are compounds of matter (bulê) and form (morphê or eidos), easily illustrated, as Aristotle himself does, by a statue: the bronze of a statue is its matter and the shape its form. One and the same quantity of matter might be now a statue of Hermes and now a statue of Aphrodite, because it might first be informed with a Hermes-shape only later to be put into a smelter and recast so as to be informed with an Aphrodite-shape. This underscores Aristotle's talk of the matter's being potential (dunamis) and the form's being the actuality (entelecheia). The same bronze is now actually a statue of Hermes in virtue of one form and later actually a statue of Aphrodite in virtue of another form: the form actualizes the matter, the bronze. By contrast, the bronze seems all along potentially one or the other, indifferently. That is, even while it constitutes a statue of Hermes, the quantity of bronze retains the capacity to be a statue of Aphrodite. Further, because the statue of Hermes itself cannot constitute a statue of Aphrodite, it appears that the matter, the bronze, is not identical to the statute it constitutes. In short, the statue and the bronze which constitutes it have different modal profiles. Altogether, then, neither metaphysical component of the statue, the matter or form, is identical with the other component of the statue, or, indeed, with the compound statue as a whole. Only the statue itself, the hylomorphic compound of matter and form, is the complete, actual being.

Whether so much of a primer on Aristotle's hylomorphism suffices to quell Gassendi's rage about the notion of actuality one cannot know. It should, however, suffice to put us into a position to understand one still more distinctive and seemingly idiosyncratic notion in Aristotle's account of the living animal: its body, the matter of the soul, its form, must, he insists, be

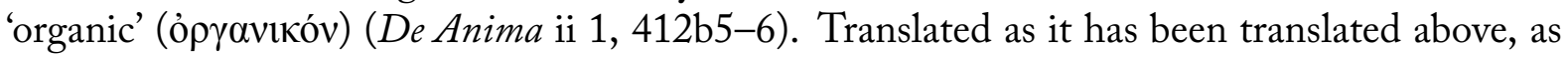
'the first actuality of an organic natural body,' Aristotle's Greek may sound utterly perverse to an untutored ear: 'organic' these days means something very different, used as it is mainly of vegetables and other agricultural produce to indicate a provenance whereby they have been grown without artificial chemical additives and in an environmentally responsible manner. Obviously, that is not the point Aristotle has in view here. Still, it is not entirely clear what, then, it is. To see his point, we need reflect on his notion of the body as potential (dunamis). When we say that the same quantity of bronze is potentially a statue either of Hermes or Aphrodite, we are saying more than that it is possibly enformed by either, though we are saying at least that much. In addition, for something to be potentially $\phi$, that something must already be actually $\psi$; it must have some actual feature undergirding its ability to become actually $\phi$. Bronze is potentially a statue of Hermes in view of its density and malleability, whereas liquid nitrogen is not. Neither are, say, the sound waves produced by the brass section of the Berlin Philharmonic in a concert performance of Wagner's Götterdämmerung. In neither case is the material stuff suited to realize the form; in neither case does the matter have the potential, because it lacks the requisite features in actuality requisite for manifesting that potentiality.

\footnotetext{
${ }^{9}$ Gassendi (1624). For a fuller consideration of Gassendi's reaction to Aristotle's appeal to the notion of actuality in connection with his definition of motion, see Shields (2009).
} 
This last contention, about suitability given in terms of underlying actualities, goes some

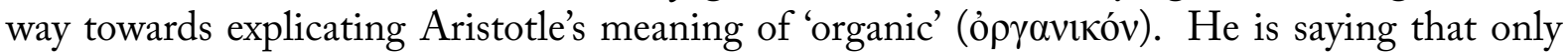
a body which is already a sophisticated sort of matter, which is already actually able to evince characteristic human activities, is able to serve as the matter of a human animal. This explains in part his lack of patience with the Pythagorean myths according to which one sort of soul might transmigrate from one body to the next, as if the material base of life activities were indifferent. As he says earlier in his De Anima:

But something absurd turns out for this account as for most others concerning the soul, since they conjoin the soul to the body and place it in the body without articulating in addition the cause of this or the condition of the body. This, however, would seem to be necessary; it is because of their commonality that one acts while the other is affected, and that the one initiates motion and the other is in motion. None of this belongs to things which just happen to be related to one another. These accounts merely endeavour to say what sort of thing the soul is without articulating anything further about the body which is to receive the soul, as if it were possible, as according to the Pythagorean myths, for just any soul to be outfitted in just any body. For each body seems to have its own peculiar form and shape, and what they say is almost the same as if someone were to say that carpentry could clothe itself in flutes; for it is necessary that the craft make use of its tools (dei gar tên men technên chrêsthai tois organois) and that the soul make use of its body. (De Anima i 3, 407b13-26).

Only bodies suited to manifest various sort of appropriate functions qualify as material bases of forms which render them actually the matter of the compounds they are.

Here it is key to notice one neglected feature of Aristotle's hylomorphism, a point which emerges clearly in the end of his dismissal of the Pythagoreans: as a carpenter cannot use flutes to ply his trade, needing to use instead suitable task-specific tools (ópy $\alpha v \alpha$ ), so a soul cannot use just any body to realize the activities of life, but needs a body which is, so to speak, toolish or suited to be a tool for its ends. Some such rendering is, it seems, the most literal rendering of opyavikóv. A body is organic because it is an organ of the soul. In the original meaning of the term, something qualifies as organic because it is the right sort of dedicated tool, which in turn it is only in virtue of what it already actually is - a saw and not a flute, or a flesh, bone, and blood arrayed in a certain way and equipped with organs and not a lump of clay. Only in virtue of some actual features can some matter qualify as potentially enformed. This brings us close, at least, to one original meaning of organic.

If this much is correct, we can specify three related consequences of Aristotle's contention that the body is organic, one negative and two positive. First the negative: something which is organic is not an organism. This reflects more than just a difference in parts of speech. Nothing we are inclined to call an organism is merely a suitable tool; on the contrary, we tend to think of organisms as independent, autonomous beings. If asked to point to an organism in a stable of horses, we will point to a horse, and not engage some manner of hylomorphic analysis before proceeding to identify the horse body which serves as the matter of the horse soul. In the original meaning of organic, it is precisely not the compound which is organic, but rather something which is toolish, namely the matter used by the form in the life activity of the compound. There is, thus, a fair distance to travel from organic to organism.

This brings us to the second consequence, now positive. Something in Aristotle's scheme qualifies as organic only if it is functionally specified: tools are the tools they are because of what they do. A spanner is a spanner and not a hammer because it is suited to turning bolts and not 
to pounding nails. We know, of course, how the tools we use came to be so suited: we designed them with specific ends in mind. In Aristotle's original notion of organic as applied to natural bodies, we find something less clear and less clearly defensible, namely that certain tools are the tools they are because they manifest functions even though no-one has designed them to have those functions. In Aristotle's system, living tools were not designed by conscious agents, but rather fashioned by nature, which, as he likes to say, 'does nothing in vain' ( $D A 415 \mathrm{~b} 15$, 434a31; Part. An. 641b12-19; Gen. An. 888b20; Pol. 125b20). To the extent that we may find such appeals to natural teleology inadmissible, we will equally find Aristotle's conception of the body as organic as no longer to be entertained in serious biological discourse.

The same holds true of the last consequence, also a positive one: precisely because it is so thoroughgoingly functional, the original notion of organic is inherently, ineliminably normative. Tools have functions, and these are functions they may execute well or poorly. Here we may distinguish two relevant ways of thinking about the normativity of tools, one external and comparative and the other internal and evaluative only with respect to an internal norm. This distinction is most easily grasped by way of an illustration. Computers are sophisticated tools. One computer, one with a $2.9 \mathrm{GHz}$ quad-core processor, executes a certain program better than another computer, one with a $2.6 \mathrm{GHz}$ dual-core processor. The first is better than the second in so far as it is faster, less prone to crashing, more streamlined. This is the external, comparative notion. At the same time, the first computer, the better one, may yet be functioning well or poorly on its own terms, perhaps because it is buggy, or has its memory stressed, or because some moisture has seeped into its processor. This is the internal notion, in terms of which we say it is functioning well, not in comparison with another computer, but simply in terms of its own internal architecture.

It is primarily in this sense that we may also say that it is perhaps malfunctioning. The lesser computer computing well within its resources is not malfunctioning in comparison with the more powerful computer; it is simply not computing as well. If the more powerful computer, by contrast is, due to a virus, computing only at the level of the less powerful computer, then it is functioning poorly, or malfunctioning. Aristotle will be prepared to speak of the whole body in these terms, as functioning or malfunctioning, with respect to the functions required for the life activities of the soul whose body it is. We do not tend to follow him in this. That is, we do not speak of our whole bodies as organs of the soul. 10 Even so, we are in the habit of speaking of parts of the body as organs. When we do so, we find ourselves appealing mainly to the second, internal aspect of normativity just identified. This we do when we say, for example, that someone's kidneys are malfunctioning, so that she needs weekly dialysis. Here talk of malfunctioning is plainly specified only against a norm of functioning well, namely that of filtering the blood of impurities, where even talk of 'impurities' is normative, as given by a norm given in terms of the health of the organism. We may set aside for the present the question of whether we should wish to regard this sort of malfunctioning as an objective, perceiver-independent feature of the natural world, or rather a subjective projection reflecting our local interests. For the present, we need only note that the notion of organ we have inherited from Aristotle's o $\rho \gamma \alpha$ vikóv is no less normative, precisely because it is no less, at root, functional.

Much more can be said about these matters of course, but let us sum up at this juncture by bringing these three features of the original notion of organic into clear view, taking them now in reverse order. First, if $x$ is organic, $x$ is inherently, ineliminably normative. This is because, second, to be organic is to be toolish, and tools, or organs, are functional kinds: tools are as

\footnotetext{
${ }^{10}$ This is not to say that notions of norms have been ignored altogether. Witness, for instance, Canguilhem (1991) and the large literature it occasioned.
} 
tools do, and they are judged as successes or failures, as functioning well or malfunctioning, only against the norms given by their functionality. Finally, then, third, what is organic here is precisely not a complete and autonomous agent. It is, instead, like an organ of a body today, a part of a complete and autonomous whole, something whose function serves the interests and well-being of the whole. Aristotle's view of the entire body as ópravıkóv, as something which serves the end of the soul, may strike us as quaint or antiquated, or both. If so, it is worth pausing to note that we nevertheless seem content to call parts of our bodies organs, and for much the same reason that Aristotle called the body organic: they have intrinsic functions providing norms against which they are habitually judged as succeeding, when they function well, and as failing, when they are malfunctioning. In this way too, however, we are like Aristotle: we do not think of the organic thing as the whole, autonomous organism. It is, rather, something in service of the organism.

\section{What Organisms Might Yet Be}

One may wonder how this excursion into ancient history may be relevant to the trumpeted return of the organism in twenty-first century biology. In one way, one may say, very little indeed. In another way, however, there is yet something instructive in making the comparison.

On the negative side, to be clear: nothing Aristotle says offers any prescription about whether organisms should be thought in any way to be an indispensable or otherwise useful concept in present-day biology. Although he was surely a very keen biologist in his day, Aristotle is no kind of party to the disputes about the fate of the organism that have characterized recent work in the field. This is a matter wholly internal to the dialectic of that science as it has progressed in the last century and, indeed, as it will continue to progress in the century to come.

Still, on the positive side there is something precautionary in Aristotle's approach. When parties to the current debate contend that organisms are making a comeback, or imply, at the other extreme, that they are not, that there simply are no organisms, then unless they are utterly and uselessly talking past one another, they must all have some shared conception as to what organisms are. After all, suppose Bric and Brac disagree about whether there are witches. Bric says no, because, he maintains, witches are women possessed of the devil, and there are no such women, not least because there is no devil. Brac demurs. On the contrary, she replies, there certainly are witches; it is just that witches have been discovered to be women with epilepsy. Fairly plainly, Bric and Brac do not seem to be disagreeing about anything substantive, if they are disagreeing about anything at all. In the same way, proponents and deniers of the existence or utility of organisms in philosophy of biology disagree only if they are talking about organisms understood in at least roughly the same terms.

Somehow, the rough and ready notion of medium-sized living animal seems not up to the task. It is true that we speak of organisms, at least in the base case, as animals, plants, or singlecelled life forms. Yet this takes us only so far. Suppose two organisms, a man and a woman, are enjoying a glass of wine after dinner. If the wine they are drinking is Sauterne, then it has likely been infected by colonies of Botrytis cinerea, with their asexual spores of Hyaline conido borne on branching conidiophores. How many individual organisms do we have, exactly? We may be at a loss to say. Perhaps we need not be exact here, but to the extent that we wish to speak of organisms at all, we might well wish to know how in principle we might become exact in our knowledge, or, failing that, why precision in this domain is unattainable. Note that these sorts of questions are pertinent to all parties to the debate. When the detractor says that there are no organisms in view here, because there are no organisms, then she is denying the existence 
of something, as surely as we deny the existence of something when we say that there is no Pegasus: we are denying the existence of flying horses. Same again for the milder critic who is simply reporting that biology as practiced has no need for explanatory posits at the level of the organism. For he too is saying that biology has no need of something-namely, the very thing which the champions of the role of organisms affirm. So, unless we are all arguing at cross purposes, some denying and some affirming the existence of organisms without first agreeing about what is being affirmed or denied, then we must have some shared conception of what organisms might be.

What might that conception be? Here the Aristotelian notion may seem precisely ill-suited to lend illumination. For if what we have said is correct even in rough outline, then when Aristotle appeals to the notion of a body as organic, he was speaking not of the whole animal, the whole independent living being, but of the animal's body, and he meant not that the body was some manner of living being, but rather something fitted to serve as a tool of the soul, that the body was so organized that it could serve the purposes of the soul and so be used to implement the soul's several ends. He meant, in a word, that the body was instrumental. The contrast is plain. An organon is a tool and a tool is ever a tool for something, an instrument whose unity is given by its use, by the function it performs; an organism, a living being, is not a tool, and indeed arguably qualifies as a living being at least in part because it is not for anything at all. We are, after all, rightly offended when we hear Aristotle calling a slave a 'living tool' (cf. Nicomachean Ethics viii 10, 1161b4-7; cf. Politics i, 1253b28-1254a17), a phrase apt to seem for us practically oxymoronic.

The core problem is that the notion of being organic has given way to some thing's being an organism in such a way that an organism seems somehow autonomous and functionless, precisely, then, the sort of thing that might use a tool rather than be a tool. Along the way, one might suppose, the word organon has been severed from its teleological moorings.

There are nevertheless five prescriptions one might glean from Aristotle's approach for our thinking about the status of organisms. First, one may say that what was once a dependent entity has become an ontologically independent entity. In the passage from ópyavov to organism, the latter became not what Aristotle thought the body to be, but rather what he regarded as the compound of soul and body - the substance (basic being, ousia). That is something, though, he thought of as having its own life directionality. Still, to the degree that this is so, disputes about organisms begin to look very much like disputes about substances, which are held by this tradition to be paradigmatic ontologically independent beings. Looked at this way, what divides at least two of the camps in disputes about the role of organisms, between the eliminativists, like Ruse in one mood, and the champions of the organism in the other, in fact takes up an altogether traditional debate about whether or not there are substances, and then, if so, in what their ontological independence might consist. Here one is put in mind of Sydney Shoemaker's remark, in another context, that 'Nowadays the question whether the self is a substance, and whether the identity over time of a person requires the identity of a substance, has a musty smell to it' (1997, 283). If we swap out the word 'organism' for 'self' and 'person,' we might think much the same. Progress will likely be made in this dispute only when its participants come to terms with the ontology of substance.11]

\footnotetext{
${ }^{11}$ Here too mutatis mutandis is Shoemaker $(1997,283)$ instructive: 'There is always a danger that framing a current philosophical issue in traditional metaphysical terms-here, in terms of the concepts of substance, inherence, etc.-will result in obfuscation rather than clarification. But that is a risk I shall take. I shall try to show that it is possible to combine some of the central intuitions that go with the claim that the self is a substance with some, although certainly not all, of the intuitions that go with
} 
Second, this is in part because questions about living substances forever invite contrasts with artefacts. Substance theorists squabble amongst themselves about the question of whether only living beings qualify as substances. ${ }^{12}$ This becomes especially pressing in the discussion of organisms, because we are now in a position to create them ourselves, blurring one traditional line between 'organic beings' - for so the term has come to be used ${ }^{[13}$ — and artefacts. When scientists synthesized a eukaryotic chromosome for the first time in producing a functional chromosome of baker's yeast, some were inclined to see the distinction between organisms and artefacts as permanently blurred. Which distinction, though, was that? What were the organisms that were, as organisms, contrasted with artefacts? And on what justifiable basis, if any, were they so contrasted? The dispute is immediately redolent of a dispute in the theory of substance; arguably progress will be made only when the larger categorial features of that larger debate are acknowledged and overtly reintroduced.

The same holds true with respect to our attitudes towards organisms as living beings, and this is the third consequence of note. We think that $x$ is an organism only if it is living. Opinions then divide as to whether life admits of a non-stipulative, non-arbitrary, essence-specifying definition. Some suppose that it can, and some rejoin that this is merely a matter of stipulation. It depends, they say, upon what one means by 'life'; so, we might say, our questions depend upon what one means by 'organism'. Just so, it seems-but those who have not given up on the task of providing a non-stipulative definition of life do not regard the conversation as thus ended. It does depend upon the meaning of life; yet the meaning of life sought is not lexical meaning or a matter of mere stipulation. On the contrary, they return, life does admit of a definition, or, at the very least, is not shown not to admit of an essence-specifying definition by those who simply lazily and smugly assert that it cannot. 14 Especially those working in areas of artificial life have, then, much to offer those reflecting on the nature of organisms. For organisms seem, on their surface, to be essentially living beings.

Fourth, in so far as questions about organisms are implicated in questions about living systems, they are also implicated in discussions of teleology. This is so, at any rate, if accounts of living systems are themselves implicated in questions about teleology. Living systems seem to many inherently normative, ${ }^{15}$ such that it makes sense to inquire of every living system whether it is flourishing. To some, this may seem positively deadly to the enterprise, relying as it does on a normative notion, alien to the framework of empirical, descriptive biology. These are large questions of course, which we do not attempt to settle. Instead, one can observe that if any account of organisms must rely upon some account of life, and if life is itself inherently normative, and indeed inherently normative by being inherently teleological, then if such notions have no home in empirical biology, it will follow that neither will organisms, and the eliminativists will have been proven correct. One notes, however, that the antecedents of these conditionals do not seem to be themselves straightforwardly empirical matters. To the degree that this is so, then, it seems that the allegedly empirically driven rejection of organisms in biology will have relied on some principles which are themselves at least covertly non-empirical after all.

Be that as it may, on its migration from ópyavov to organism, the notion in view seems not to have shed its normativity. To repeat, only briefly, a point made earlier: if we are insisting on

reductionist views about personal identity.'

${ }^{12}$ For an argument offering an affirmative answer to this question, see Shields (2008).

${ }^{13}$ Here the exchange between Putnam (1964) and Ziff (1960) as to whether mechanical rose plants might be alive becomes instructive. See also Matthews (1997) and Shields (2008).

${ }^{14}$ For accounts of the nature of living systems, see Shields (2012) and especially Bedau (1992, 1998).

${ }^{15}$ See Shields (2012) and Bedau (1992). 
normativity in our notions of what it is to be an organism, we are not thereby supposing that the normativity in question is mind-independent. Surely Aristotle thought it was, but those who employ his idioms in these debates are not beholden to him in this respect. This seems, however, a debate for another day. At present, one might merely note that those approaches to organisms flowing directly out of contemporary biology given in terms of their being immunological centers evidently appeal directly to two features given by the friends of teleology, namely normativity and norm-driven unity.10 Questions about the norms employed in discussions of immunological centres are thus subject to precisely the same debates. If an immune system may be compromised, or damaged, then there is an implicit contrast being drawn and given in terms of a norm: it is no longer operating at its best. Those party to these ways of speaking may then join the debate about whether the norms to which they appeal are mind-independent or projected by their own interests. It seems difficult, however, to allow them to claim that they are in fact not appealing to norms at all.

Still, one can appreciate more locally, fifth, at least one modest advantage to grasping the nettle here and allowing that organisms are essentially living, while living systems are essentially normative, and, indeed, normative in some recognizably teleological way. For as some proponents of this approach to life have argued, 17 approaching the matter this way has the welcome advantage of introducing a wanted scalarity into our discussions of what it is to be an organism. If living systems may be more or less living systems by being more or less teleonomic systems - and the notion of teleonomicity is itself scalar-then the question of whether something qualifies as an organism or not need not be answered rigidly, by insisting that something is crisply on one side of the fence or the other. On the contrary, the theory will predict that some things are more organisms than other things, that some things clearly are not organisms, and that some things hover on the boundary. This, however, seems to capture the actual attitudes of empirical scientists implicated in making such determinations. In sum, we need not, indeed we should not, approach questions about the nature of organisms armed with the false presupposition that the question demands an all-or-nothing specification given in terms of some plainly stated necessary and sufficient conditions.

\section{Conclusions}

We should not suppose that what organisms once were determines what they now must be, or even indeed that they now must be at all. Still, when we see what it has meant in other, older contexts to be organic, we can also begin to see what organisms now may yet be. We have seen that the notion of organicity has migrated in surprising and instructive ways: what were dependent entities have given way to ontologically independent entities, that what once were tools instrumental to ends beyond themselves are now themselves the beneficiaries of subordinate organs which are their parts. Along the way, however, the notion of teleonomic unity, core to the notion of something oganikon, has not fallen by the wayside. On the contrary, to be an organism is to be a unified living being, a being whose unity is given in unapologetically normative terms.

Whether biology as it is or will be finds use for explanations at the level of organisms is, to be sure, a matter for biologists to determine amongst themselves. Even so, these investigations suggest that it is unlikely that organisms will go the way of phlogiston or witches. They will, on the contrary, likely remain with us, in one form or another. Accordingly, it behoves us to reflect

\footnotetext{
${ }^{16}$ For an engaging approach to organisms as immunological centers, see Pradeu (2010).

${ }^{17}$ See Shields (2012).
} 
on the question of what organisms may yet be; presumably this will prove to be something not too radically removed from what they once were.

\section{Acknowledgments}

I thank Colin Shields and Allison Murphy for discussion of early drafts of this essay. A distant ancestor to those drafts was offered in Paris, at a conference on the topic of organisms organized by Thomas Pradeu and Adam Ferner. I learned a great deal at that conference-so much, in fact, that my paper needed to be extensively rewritten after attending. I am grateful to the organizers first for their kindly invitation and then also for the subsequent comments on drafts of the revised paper. Comments by several other participants, including most notably David Wiggins, also helped clarify my thinking about these matters; I am grateful to them all. The penultimate draft was read carefully and to good effect by Charles Wolfe, whose remarkable command of the pertinent issues and relevant literatures proved immensely helpful. While I am confident that I have not met all of the challenges set in his far-reaching remarks, I am equally confident that this paper has been improved substantially due to reflection on the perceptive, generous counsel he offered.

\section{Literature cited}

Bedau, M. 1992. “Where's the Good in Teleology?” Philosophy and Phenomenological Research 52: 781896.

1998. “Four Puzzles about Life.” Artificial Life 4: 125-140.

Canguilheim, G. (1979) 1991. Le Normal et la Pathologique. Paris: Presses Univisitaires de France. Translated by C. Fawcett as The Normal and the Pathological. Cambridge, MA: MIT Press.

Cheung, T. 2006. "From the Organism of a Body to the Body of an Organism: Occurrence and Meaning of the Word 'Organism' from the Seventeenth to the Nineteenth Centuries." British Journal for the History of Science 39 (3): 319-339.

2010. "What is an "Organism"? On the Occurrence of a New Term and Its Conceptual Transformations 1680-1850.” History and Philosophy of the Life Sciences 32 (2/3): 155-194.

Gassendi, P., Exercises against the Aristotelians [Exercitationes paradoxicae adversus Aristoteleos] II. 2, 4.

Godfrey-Smith, P. 2009. Darwinian Populations and Natural Selection. Oxford: Oxford University Press.

Jablonka, E., and M. J. Lamb. 1995. Epigenetic Inheritance and Evolution: The Lamarckian Dimension. Oxford: Oxford University Press.

Lamb, J. F., C. G. Ingram, I. A. Johnston, and R. M. Pitman. 1984. Essentials of Physiology. 2nd edition. Oxford: Blackwell.

Matthews, G. 1977. "Consciousness and Life." Philosophy 52: 13-26.

Mossio, M., and A. Moreno. 2014. Biological Autonomy: A Philosophical and Theoretical Enquiry. Springer Verlag.

Nicholson, D. 2014. "The Return of the Organism as a Fundamental Explanatory Concept in Biology." Philosophy Compass 9: 347-359.

OED Online. 2016. “organism, n.” Oxford University Press. http://www.oed.com (accessed March 12, 2017).

Oyama, S. 2000. The Ontogeny of Information. 2nd ed. Durham, NC: Duke University Press. 
Oyama, S. et al. 2001. "Cycles of Contingency: Developmental Systems and Evolution." Cambridge, MA: MIT Press.

Peterson, E. 2014. "The Conquest of Vitalism or the Eclipse of Organicism? The 1930s Cambridge Organizer Project and the Social Network of Mid-twentieth-century Biology." British Journal for the History of Science 47: 281-304.

Pradeu, T. 2010. "What is an Organism? An Immunological Answer." History and Philosophy of the Life Sciences 32: 247-267.

Putnam, H. 1964. "Robots: Machines or Artificially Created Life?” Journal of Philosophy 61: 668-691.

Ruse, M. 1989. “Do organisms exist?” American Zoologist 29: 1061-1066.

Shields, C. 2009. "An Approach to Aristotelian Actuality." In Mind, Method and Morality: Essays in Honour of Anthony Kenny, edited by P. Hacker and J. Cottingham, 68-93. Oxford: Oxford University Press.

- 2012. "The Dialectic of Life." Synthese 185: 103-124.

Shoemaker, S. 1997. "Self and Substance." Nồs 31: 283-304.

Walsh, D. 2006. "Organisms as Natural Purposes: The Contemporary Evolutionary Perspective." Studies in History Philosophy, Biological and Biomedical Science 37: 771-791.

—. 2010. "Two Neo-Darwinisms." History and Philosophy of the Life Sciences 32 (2/3): 317-339.

- 2012. "Mechanism and Purpose: A Case for Natural Teleology." Studies in History and Philosophy of Biological and Biomedical Sciences 43: 173-18.

- 2014. "Function and Teleology." In Evolutionary Biology: Conceptual, Ethical and Religious Issues, edited by R. Thompson, and D. Walsh, 193-216. Cambridge: Cambridge University Press.

Webster, G., and B. C. Goodwin. 1982. “The Origin of Species: A Structuralist Approach.” Journal of Social and Biological Structures 5 (1): 15-47.

Ziff, P. 1960. Semantic Analysis. Ithaca: Cornell University Press.

(C) 2017 Author(s)

This is an open-access article distributed under the terms of the Creative Commons AttributionNonCommercial-NoDerivatives 4.0 International license, which permits anyone to download, copy, distribute, or display the full text without asking for permission, provided that the creator(s) are given full credit, no derivative works are created, and the work is not used for commercial purposes.

ISSN 2475-3025 